\title{
Attainment ages of smiling and walking are early predictors of developmental delay in preterm children
}

\author{
Nienke H. van Dokkum ${ }^{1,2}$, Arend F. Bos ${ }^{1}$, Sijmen A. Reijneveld², Marlou L.A. de Kroon² \\ 1 Dept of Pediatrics, Division of Neonatology, Beatrix Children's Hospital, and 2 Dept of Health Sciences, University Medical Center, \\ University of Groningen, Groningen, the Netherlands. Authors have nothing to disclose
}

\section{Background}

Early identification of developmental delay might enhance opportunities for timely targeted interventions, especially for preterm children. Besides known demographic predictors, later onset of smiling and walking might be add-on predictors of developmental delay in both motor and cognitive function.

\section{Aims}

To examine

a) Whether later onset of smiling and walking are early indicators of developmental delay

b) Whether these milestones contribute to a good clinical prediction model for increased risks of developmental delay

\section{Methods}

- Community based cohort study LOLLIPOP\$ ('02-'03).

- 1,605 children with a recorded smiling-age and/or walking-age (demographic characteristics in Table 1).

- Parents reported the calendar smiling-age \& walking-age.

- Development at age 4 was assessed by the parent-reported Ages \& Stages Questionnaire (ASQ).

Statistics:

- Predictive value of smiling-age \& walking-age was determined by logistic regression analyses.

- Prediction model: Backwards selection was performed using logistic regression (conform Akaike Information Criterion, $p<0.157$ ). The model fit was determined by the Hosmer-Lemeshow test. Performance was determined by the Area Under the Curve (AUC) under the Receiver Operating Curve (ROC) and Nagelkerke's $\mathrm{R}^{2}$. Internal validation was performed by correction for optimism \& shrinkage factor using bootstrapping techniques.

Table 1. Participant characteristics (N [\%]) for children with a recorded smiling-age and/or walking-age $(\mathrm{N}=1,605)$.

\begin{tabular}{|c|c|c|c|}
\hline & $\frac{\begin{array}{r}\text { Early } \\
\text { preterm }\end{array}}{(\mathrm{N}=424)}$ & $\frac{\text { Moderately }}{\frac{\text { preterm }}{(\mathrm{N}=769)}}$ & $\underline{\text { Fullterm }}$ \\
\hline Gestational age (wks)\% & $29.1(1.96)$ & $34.0(1.04)$ & $39.6(1.00)$ \\
\hline Birth weight $(\mathrm{g})^{\%}$ & $1294(363)$ & $2240(469)$ & $3543(493)$ \\
\hline SGA & 93 (21.9) & $65(8.4)$ & $32(6.8)$ \\
\hline Male gender & 227 (53.5) & 448 (58.3) & $222(47.0)$ \\
\hline Non-Dutch Ethnicity & $20(5.7)$ & $35(5.3)$ & $20(4.9)$ \\
\hline Low/middle maternal education & $258(72.9)$ & $500(74.5)$ & $293(70.9)$ \\
\hline Reported smiling-age & $132(31.1)$ & $313(40.7)$ & $201(42.6)$ \\
\hline Reported walking-age & $395(93.2)$ & $685(89.1)$ & $425(90.0)$ \\
\hline
\end{tabular}

\section{Results}

- Every week later onset smiling-age increased the risk of communication delay with $17 \%$ \& increased the risk of gross motor delay with $16 \%$.

- Every month later onset walking-age increased the risk of gross motor delay with $18 \%$ and increased the risk of general delay with $14 \%$.

- Our final prediction model includes smiling-age, walking-age, ethnicity, gender \& maternal educational level and had a good fit ( $p=0.353$ ), with relatively good performance (corrected AUC 0.773), R² 19.3\%.

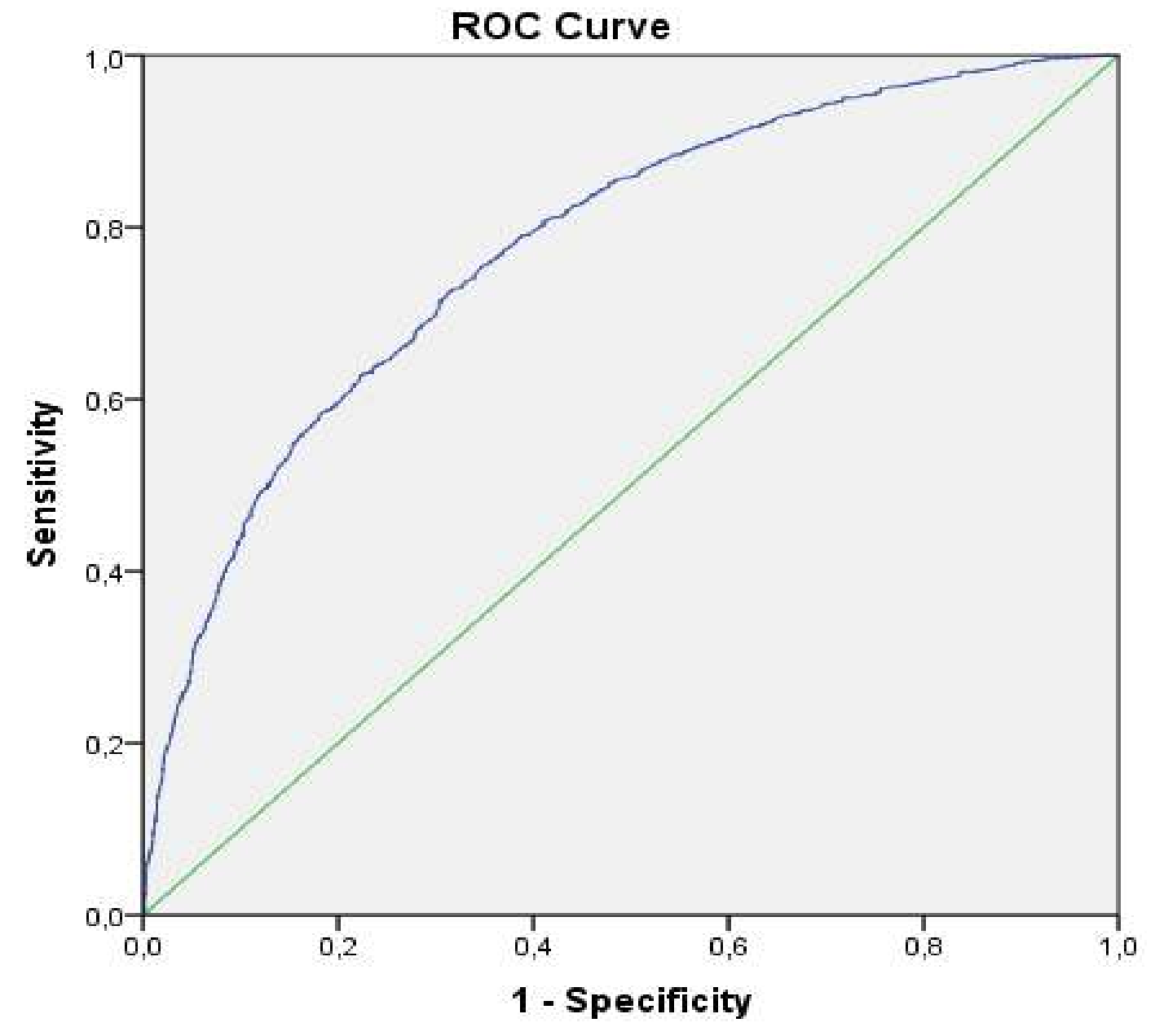

Diagonal segments are produced by ties

Figure 1. ROC for probability of general developmental delay at age 4

Linear predictor for the probability of an abnormal ASQ total score: $0.14^{*}$ smiling-age $+0.12^{*}$ walking-age $+1.26^{*}$ gender $+0.64^{*}$ ethnicity + $0.84^{*}$ maternal_educational_level-7.17.

Table 2. Multivariable odds ratios of abnormal ASQ-domain and total scores for each week a child has its first smile and each month a child walks its first steps.

\begin{tabular}{|c|c|c|c|c|}
\hline \multirow[b]{2}{*}{$\underline{\mathrm{ASQ}}$} & \multicolumn{2}{|c|}{ Smiling-age } & \multicolumn{2}{|c|}{ Walking-age } \\
\hline & $\underline{\mathrm{aOR}}$ & $95 \%-\mathrm{Cl}$ & $\mathrm{aOR}$ & $\underline{95 \%-\mathrm{Cl}}$ \\
\hline Communication & 1.17 & $1.03-1.33^{\star}$ & 1.06 & $0.99-1.12^{\#}$ \\
\hline Personal Social & 1.08 & $0.93-1.27$ & 1.11 & $1.04-1.19^{\star *}$ \\
\hline Problem Solving & 1.16 & $0.98-1.37$ & 1.06 & $0.99-1.14$ \\
\hline Fine Motor & 1.02 & $0.89-1.17$ & 1.12 & $1.05-1.19^{\star \star \star}$ \\
\hline Gross Motor & 1.16 & $1.01-1.32^{*}$ & 1.19 & $1.11-1.27^{\star \star \star}$ \\
\hline Total problems & 1.14 & $1.00-1.30^{\#}$ & 1.14 & $1.07-1.21^{\star \star \star}$ \\
\hline
\end{tabular}

aOR: adjusted odds ratio for GA and covariates; $95 \%-C l: 95 \%$ confidence interval R2: explained variance. Covariates: gender, SGA, maternal educational level, ethnicity. ${ }^{* \star *} P<0.001,{ }^{\star *} P<0.01$, ${ }^{*} P<0.05, \# P<0.10$

\section{Conclusions}

Later onset of smiling and walking contribute to the early prediction of developmental delay in preterm children. Our prediction model aids professionals in risk selection, especially in well-child settings. 